\title{
Evaluation of Serum Leptin Level in Correlation with CRP in a Sample of Iraqi Patients with Inflammatory Bowel Disease at Gastroenterology and Hepatology Teaching Hospital
}

\author{
Ali S. Musa Al Shammaa ${ }^{1}$, Ghaith Sael Mohammed Ali ${ }^{2}$ Haitham Kaddouri Hussein ${ }^{3}$ \\ ${ }^{1}$ Lecturer, College of Medicine, Al-Nahraine University/Iraq, ${ }^{2}$ Lecturer, College of Medicine, Al-Nahraine \\ University/Iraq, ${ }^{3}$ Consultant/ Department of General Surgery, Khadymia Teaching hospital/Iraq
}

\begin{abstract}
Introduction: adipocytokines display avital role in inflammation and metabolism, body metabolism changes in inflammatory bowel disease (IBD) and chronic inflammation conceder the pathognomonic of this disease, s. leptin and C-Reactive protein (CRP( in patients with active disease either Crohn disease or ulcerative colitis. The aim of this descriptive study is to evaluate the serum leptin and CRP level in a sample of Iraqi patients with IBD of variable disease activity index. METHOD: serum concentration of leptin was studied in 79 patients diagnosed as IBD [41 patients diagnosed as Crohn's disease (CD) and in 38 patients diagnosed as ulcerative colitis (UC)]. The diagnosis based on colonoscopy, CT, MRI, US and histopathological examination of mucosa. Serum leptin and CRP was measured by an indirect ELISA. Leptin level was compared with CRP and correlated with disease activity. RESULTS: data showed that out of 38 patients diagnosed as UC, $10(26.3 \%)$ were in remission, $22(57.9 \%)$ were in moderate activity, and $6(15.8 \%)$ have severely active disease. On the other hand, out of 41 patients diagnosed as CD, 17 (41.5\%) were in remission state, 20 (48.8\%) have moderate active disease, and $4(9.8 \%)$ have severely active form. Serum leptin in the UC group was significantly associated with disease activity in an inverse pattern ( $p=$ 0.045), while no significant association between action index in patients with Crohn disease and leptin level $\mathrm{P}$-value $=0.77$. While $\mathrm{CPR}$ level have significant association with ulcerative colitis patients $\mathrm{P}$-value $=0.017$ and with Crohn disease $\mathrm{P}$-value $=0.043$. Comparing both CRP and leptin level showed significant association with $\mathrm{UC}$ as an overall effect and those in decrease only ( $\mathrm{P}$-value $=0.047,0.029$ correspondingly), while this association was only significant as an overall effect for $\mathrm{CD}$ group $\mathrm{P}$-value $=0.043$. conclusion: a significant association between disease activity in UC and CD with serum CRP. Comparing both CRP and leptin level showed that there is an overall significant association with both $U C$ and $C D$, but not useful for defining their activity index.
\end{abstract}

Keys words: serum leptin, CRP, Iraqi patients, inflammatory bowel disease, Hepatology Teaching Hospital.

\section{Introduction}

Inflammatory bowel disease (IBD) can divided into two types Crohn's disease and ulcerative colitis, it define as chronic immune disease inflammatory in nature of gut, incidence of it very universally ${ }^{(1)}$. Unclear pathophysiological mechanism but with many studies they recommends a multifactorial causes ${ }^{(2)}$, some studies connected it with nature of food consumption, high energy loss and decrease absorption of food and minerals ${ }^{(3)}$. CD with features of weight loss and loss of appetite during acute stages of inflammation (4-7).
Traditionally, management of IBD was mainly depended on the presenting symptoms such as abdominal pain, bowel habits, and general well-being. Symptomatic treatment, however, may not improve long-term results or slow disease progression ${ }^{(8)}$. CRP used as substitute indicators of endoscopic IBD action, it conceders one of many plasma proteins that have significant action in serious stage of inflammatory action ${ }^{(9)}$, it created in the hepatocytes and also extra-hepatic also been established ${ }^{(10,11)}$. CRP half-life is 19 hours and the level of it decrease quickly when acute phase end, so conceder vital sign of inflammation ${ }^{(12)}$. CRP action 
independent in physiological and pathological situations so CRP produced by liver conceder a single agent so it is important factor to diagnosis and screen CD patients (12). Leptin from the Greek word leptos, meaning 'thin' was first proposed in 1953 that it could be a marker of fat tissue regulation ${ }^{(13)}$, later Zhang et al isolated the leptin hormone in $1994^{(14)}$. It have important function to food intake rule, energy spending, and body weight, its receptors are expressed in a variety of tissues ${ }^{(15)}$. Leptin is considered a multi-task hormone ${ }^{(16)}$, as well as an important regulator of inflammation (17). Some of its immunological tasks includes increasing the synthetic activity and chemotaxis of macrophages and monocytes, induces the proliferation, activation and maturation of natural killer cells. Besides, leptin has non immunological tasks like regulation of food intake and digestion, regulation of metabolism, and angiogenesis ${ }^{(17,18)}$. So the aim is to assess the serum leptin level in association with CRP in a sample of Iraqi patients with IBD of variable disease activity index referred to The Gastroenterology \& Hepatology Teaching Hospital/ Baghdad.

\section{Methods}

Out of 88 patients diagnosed with IBD, referred to the GIT and Hepatology Hospital/Medical City at Baghdad from December, 2015 to October, 2016, 79 patients who fulfill the inclusion criteria were involved in this study, 38 with ulcerative colitis, and 41 diagnosed as a Crohn's disease. Exclusion criteria: (Patients diagnosed with diseases that may affect the serum leptin level such as liver cirrhosis, emaciated patients, malignant diseases or patients on chemotherapy or radiotherapy ${ }^{(18)}$, Diabetes mellitus on insulin therapy as insulin use may increase leptin level ${ }^{(19)}$, Obese patients (BMI more than 30) ${ }^{(18)}$, Lack of participant agreement and patients who did total colectomy). All patients were interviewed, clinical history, and proper examination was done. The diagnosis based on colonoscopy, CT, MRI, US and histopathological examination of mucosa. Patients with UC were separated into three clusters conferring to their disease action and by referring to ulcerative colitis disease activity score (UCDA Index) ${ }^{(20)}$ : (remission and mild disease: UCDA Index $\leq 4$, moderate disease: UCDA Index 4-10, severe disease: UCDA Index > 10).
Regarding CD, assessment of action of disease by use (CDAI) Crohn's Disease Activity Index (21). Patients were categorized into three collections: remission and mild disease $<220$ points, moderate 220 - 450, severe $>$ 450. Fasting serum leptin were collected from subjects at morning. Centrifuged of blood for 10 mins and then accumulate and serum tasters were directly cold at -48 c. Various methods for the estimation of body fat are available such as calculation of body mass index (weight (kg) divided by the square of height (m)) (BMI). So, the reference range of serum leptin differ from patient to other depending on the BMI, gender, and age group, for this reason patients divided (according to their leptin level) into three groups: (high leptin level, normal leptin level and low leptin level). Statistical analysis: t-test, for variances between the mean of 2 groups ( normal distribution), Mann W. test for variances between the mean of 2 groups ( skewed distribution), more than 2 group used K. W. test (skewed distribution). Binary logistic regression analysis used to calculate the odd ratio (OR). All data analysed by SPSS 22, P- value consider significant when less than 0.05 .

\section{Results}

Patients with UC had significantly higher BMI compared to $\mathrm{CD}$, gender also had significantly difference between $\mathrm{UC}$ and $\mathrm{CD}$, in which female to male ratio was 1.9:1 in UC and 0.64:1 in CD, serum leptin was significantly higher in UC compared to $\mathrm{CD}$.

There was no significant difference in the distribution of disease activity index and type of IBD as illustrated in table 1. In UC disease activity index significantly associated with serum leptin, in which as the disease activity increase serum leptin decrease (inverse association), while in CD no such association was observed as illustrated in table 1 . In patients with UC patients with remission had significantly lower serum CRP compared to both disease activity (moderate, severe) and in patients they had CD patients with remission had significantly lower CRP value compared to moderate and severe disease activity as illustrated in table 1 . 
Table 1 : distribution of disease action index in IBD

\begin{tabular}{|c|c|c|c|c|c|c|c|c|c|c|c|c|c|c|c|}
\hline \multicolumn{7}{|c|}{ Crohn's disease } & \multicolumn{8}{|c|}{ Ulcerative colitis } & \multirow{2}{*}{$P$ value } \\
\hline & \multicolumn{4}{|l|}{ Number } & \multicolumn{2}{|c|}{ Percent } & \multicolumn{3}{|c|}{ Number } & \multicolumn{5}{|c|}{ Percent } & \\
\hline Remission & \multicolumn{4}{|l|}{17} & \multicolumn{2}{|c|}{$41.5 \%$} & \multicolumn{3}{|l|}{10} & \multicolumn{5}{|c|}{$26.3 \%$} & \multirow{3}{*}{0.333} \\
\hline Moderate & \multicolumn{4}{|l|}{20} & \multicolumn{2}{|c|}{$48.8 \%$} & \multicolumn{3}{|l|}{22} & \multicolumn{5}{|c|}{$57.9 \%$} & \\
\hline Severe & \multicolumn{4}{|l|}{4} & 9.8 & & \multicolumn{3}{|l|}{6} & \multicolumn{5}{|c|}{$15.8 \%$} & \\
\hline \multirow{2}{*}{ Leptin level } & \multicolumn{8}{|c|}{ Ulcerative colitis } & \multicolumn{7}{|c|}{ Crohn's disease } \\
\hline & \multicolumn{2}{|l|}{ Remission } & \multicolumn{2}{|c|}{ Moderate } & \multicolumn{2}{|c|}{ Severe } & \multicolumn{2}{|c|}{ P value } & \multicolumn{2}{|c|}{ Remission } & \multicolumn{2}{|c|}{ Moderate } & \multicolumn{2}{|c|}{ Severe } & P value \\
\hline \multirow{2}{*}{ Low } & \multicolumn{2}{|l|}{0} & \multicolumn{2}{|l|}{1} & \multicolumn{2}{|l|}{3} & & & 1 & & 3 & & 1 & & \\
\hline & $0.0 \%$ & & $4.5 \%$ & & 50. & & & & $5.9 \%$ & & $15.0^{\circ}$ & & $25.0^{\circ}$ & & \\
\hline & 3 & & 10 & & 2 & & & & 10 & & 8 & & 2 & & \\
\hline & $30.0 \%$ & & 45.5 & & 33. & & & & $58.8 \%$ & & $40.0^{\circ}$ & & $50.0^{\circ}$ & & \\
\hline & 7 & & 11 & & 1 & & & & 6 & & 9 & & 1 & & \\
\hline & $70.0 \%$ & & 50.0 & & 16. & & & & $35.3 \%$ & & $45.0^{\circ}$ & & $25.0^{\circ}$ & & \\
\hline Median (IQR) & $20.2(12.9$ & & $\begin{array}{l}12.6 \\
23.4\end{array}$ & $6-$ & & $.2-$ & 0.0 & & $3.6(1$ & 8.5) & $\begin{array}{l}5.0(2 \\
15.6)\end{array}$ & & $\begin{array}{l}1.1( \\
3.3)\end{array}$ & $0.7-$ & 0.134 \\
\hline & Ulcerative & & & & & & & Cro & hn's di & & & & & & \\
\hline & Remission & Mod & ate & Sev & & $\mathbf{P} \mathbf{v}$ & & Ren & aission & Mode & rate & Seve & & P val & \\
\hline $\begin{array}{l}\text { Median } \\
\text { (IQR) }\end{array}$ & $\begin{array}{l}0.49(0.27- \\
0.80)\end{array}$ & $\begin{array}{l}1.22 \\
1.83)\end{array}$ & & $\begin{array}{l}4.98 \\
7.3)\end{array}$ & & 0.0 & & $\begin{array}{l}0.25 \\
2.0\end{array}$ & )$^{(0.15-}$ & $\begin{array}{l}1.09 \\
7.1)\end{array}$ & $0.22-$ & $\begin{array}{l}1.06 \\
7.81\end{array}$ & $0.53-$ & 0.043 & \\
\hline
\end{tabular}

P- value $<0.05$ ( significant).

Significant association between leptin and CRP in individual with UC, in subset analysis in which we divide UC into 3 groups (remission, moderate and severe disease activity), only in the patients with remission there was significant direct linear relationship between CRP and leptin, while in the other group no relationship was observed as illustrated fig. $(1,2)$. 


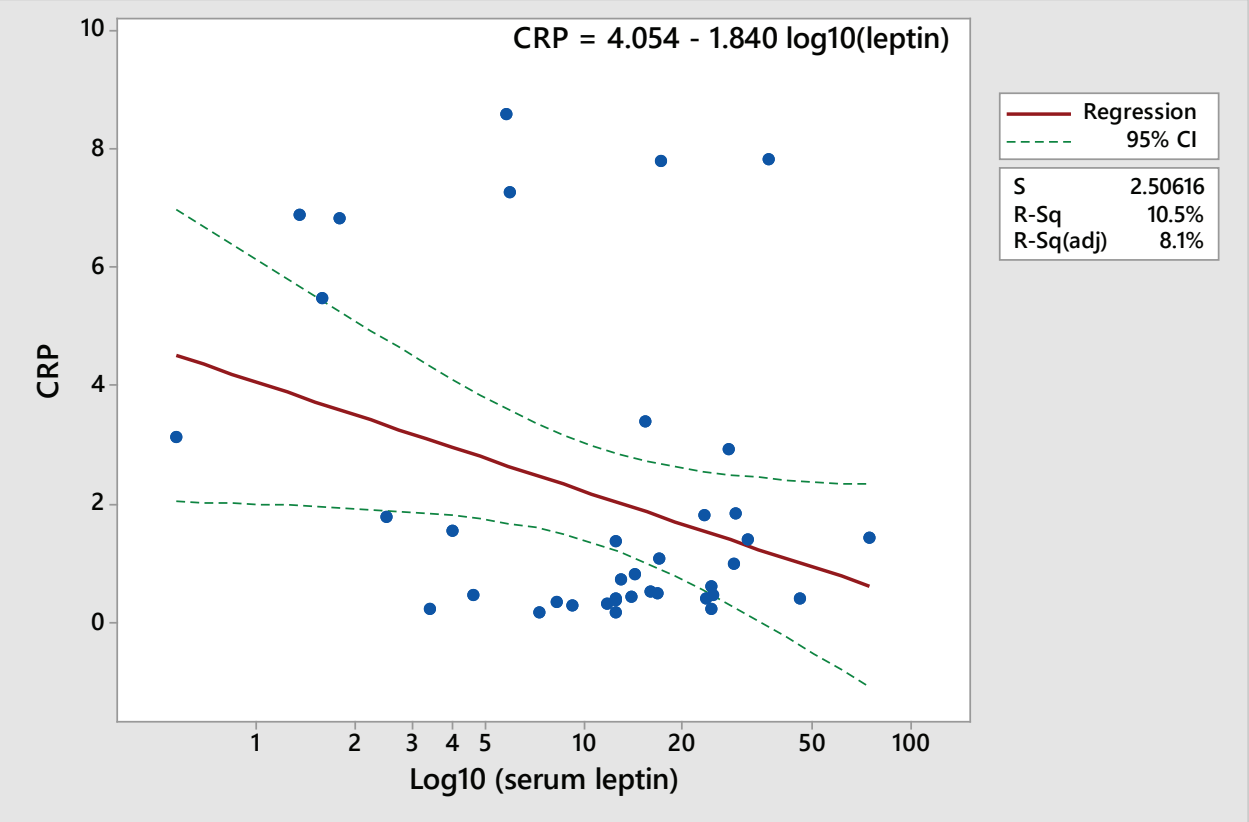

Figure 1: correlation between CRP and leptin in patients with UC (serum leptin was transformed using logarithmic scale)

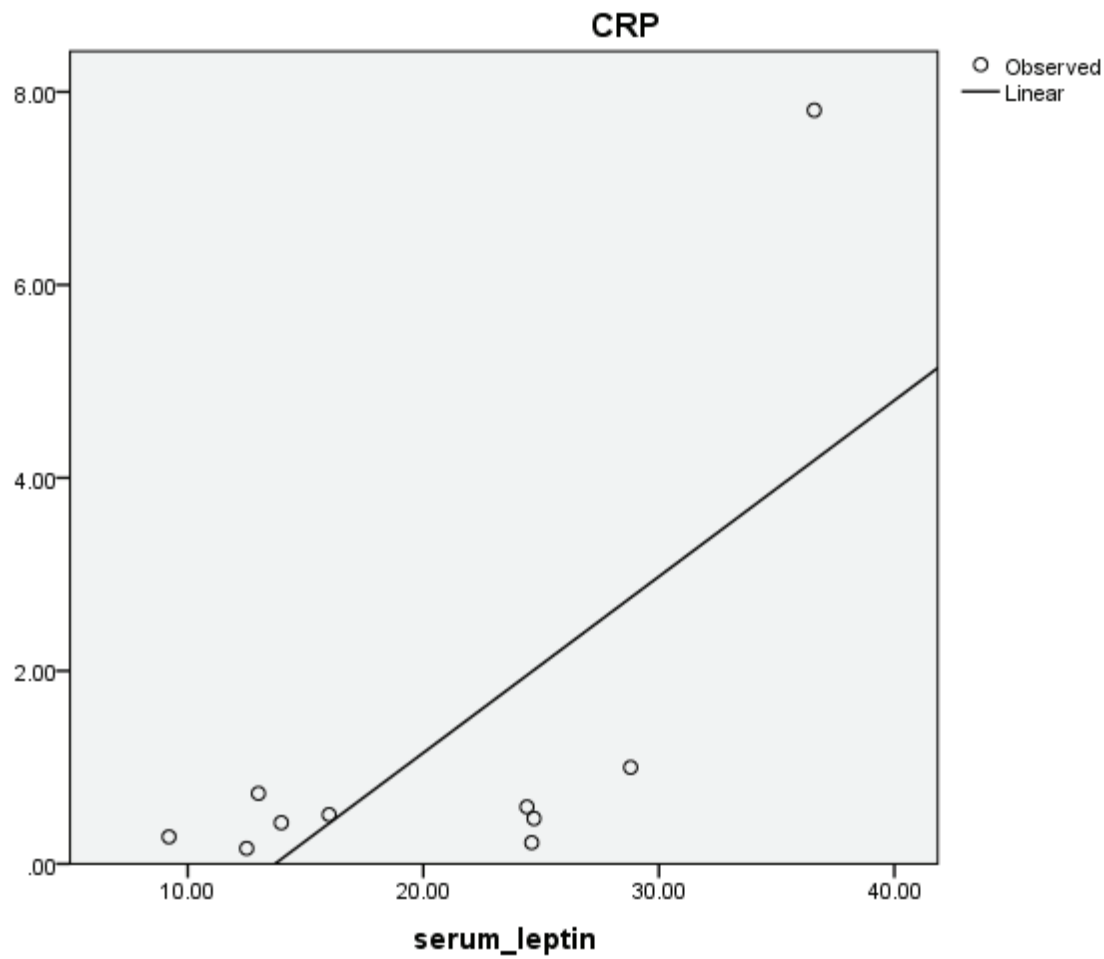

Figure 2: correlation between CRP and leptin in UC for patients with remission

Overall there was significant (direct) logistic relationship between CRP and serum leptin (see figure 3), in each of the subgroups (remission, moderate and severe), no significant association between CRP and leptin in patients with CD. 


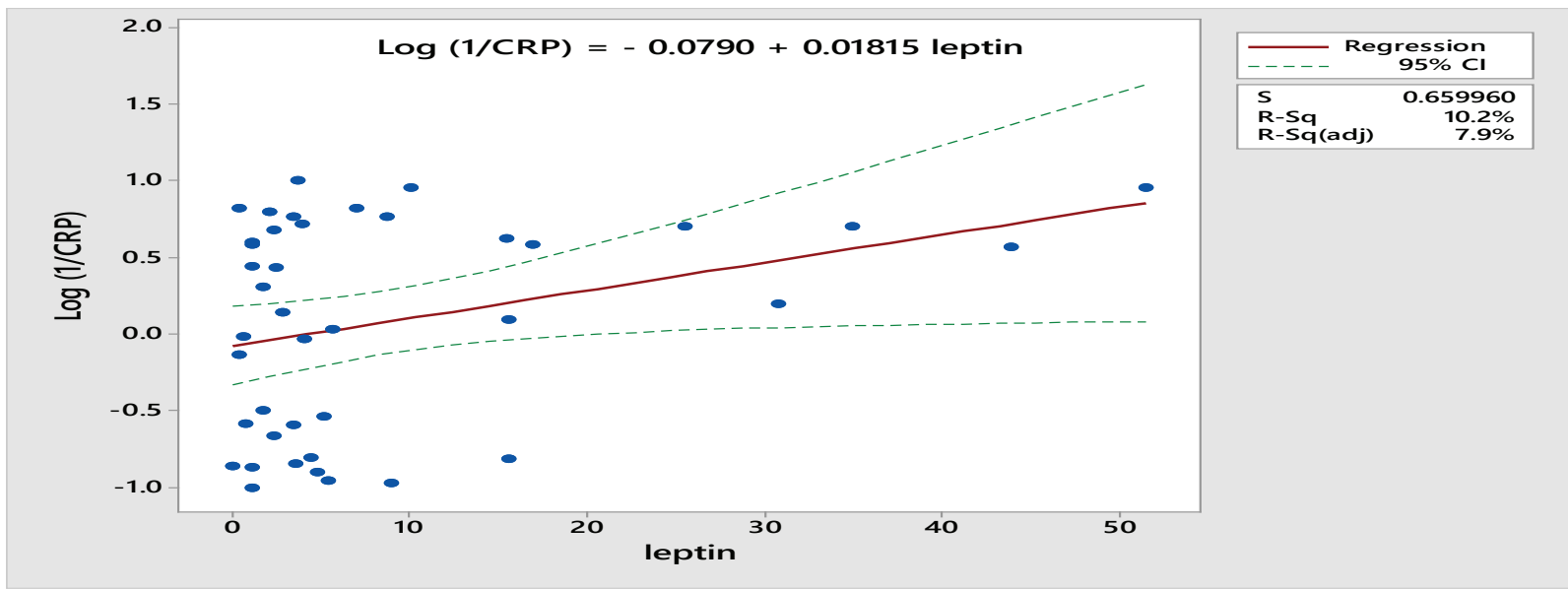

Figure 3: correlation between CRP and leptin in patients with CD (serum leptin was transformed using logistic scale).

\section{Discussion}

Causes of IBD is blurred most studies showed the disease developed as genetic basis or due to immune response to food allergens and bacteria that casing agitated intestine $^{(22)}$. The average age of patients they had IBD was 30 years old. UC can occur at any age, although diagnosis before the age of five years or after 75 years is uncommon. The peak incidence of UC occurs in the second and third decades of life ${ }^{(23)}$. Another studies show the median age was 30 years also ${ }^{(24)}$. Data reveled that there is a significant variance between patients with UC and CD by fact of gender, in which female to male ratio was $0.64: 1$ in CD and 1.9:1 in UC. many studies showed that female with less risk to have Crohn's disease, so female to male ratio was 1:3, 1:1. Our data reveled that patients with UC had significantly higher BMI compared to $\mathrm{CD}$, this might be illustrated by the reduced dietary intake and malabsorption which was more severe in patients with $\mathrm{CD}$. According to a large Chinese research done by Jie Dong et al ${ }^{(25)}$ in which 1442 patients diagnosed with IBD were involved, results showed that $\mathrm{CD}$ patients had significantly lower BMI compared to controls (95\% CI-2.77 to $-1.00, \mathrm{P}<$ 0.001 ), while no obvious difference was observed in UC patients. Our data reveled that serum leptin level was significantly upper in those patients with UC likened with $\mathrm{CD}$ patients, this may be due to the higher number of female patients with UC, since females have higher fat mass than males, which might the cause of this significant increase in leptin level. In patients with UC patients with remission had significantly lower serum CRP compared to both moderate and severe disease activity and in patients with $\mathrm{CD}$ with remission had significantly lower CRP value compared to moderate and severe disease activity, many past studies showed that CD had higher CRP level than UC patient, and high level of IL-6 (26). In our study, results showed that the relationship between disease activity and leptin level in UC group was an inverse relationship, in which when the activity of the disease increase, serum leptin level decrease, On the other hand, there was no significant relationship between leptin level and CD activity index, Studies assessing serum leptin levels in IBD activity showed controversial results ${ }^{(27)}$. In a study by Karmiris et al ${ }^{(18)}$, serum leptin levels ( s. leptin level in UC 10.6 $\pm 2.0 \mathrm{ng} /$ $\mathrm{mL}$ and in $\mathrm{CD}$ was $12.5 \pm 2.6 \mathrm{ng} / \mathrm{mL}$ ) were significantly decreased in UC patients compared to CD patients these results were nearly comparable with our study's results. In our study we compared the level of serum leptin with that of CRP in both UC and CD. Significant association between leptin and CRP in individual with UC. Results showed that only in the patients with remission there was significant direct linear relationship between CRP and leptin, while in the other group no relationship was observed ${ }^{(22)}$., there was significant (direct) logistic relationship between CRP and serum leptin, while in each of the subgroups (remission, moderate and severe) there was no significant relationship observed between CRP and leptin. there was non-significant relationship, while there was a significant one when we add CRP parameter. This means that the effect of CRP was stronger than that of serum leptin in CD patients. On the other hand the effect of leptin may be become more obvious when after adding the CRP effect as another variable, up to the date this study was established, we did not find other previous studies comparing the level of both serum leptin with that of CRP, so this study is an original one. 


\section{Conclusion}

There is a significant correlation between disease activity in UC and CD with serum CRP. Comparing both CRP and leptin level showed that there is an overall significant association with both $\mathrm{UC}$ and $\mathrm{CD}$, but not useful for defining their activity index.

Ethical Clearance: The Research Ethical Committee at scientific research by ethical approval of both environmental and health and higher education and scientific research ministries in Iraq

Conflict of Interest: The authors declare that they have no conflict of interest.

Funding: Self-funding

\section{References}

1. DK. P. Inflammatory bowel disease. N Engl J Med. 2002( [PubMed: 12167685]):347:417-29.

2. DK. P. Inflammatory bowel disease. N Engl J Med. 1991([PubMed: 1881418]):325:928-37.

3. Greenberg GR FC, Jeejeebhoy KN, et al. Controlled trial of bowel rest and nutritional support in the management of Crohn's disease. Am J Clin Nutr. 1989([PubMed: 2493735):49:573-9.

4. Ehrhardt RO LB, Gray B, et al. Induction and prevention of colonic inflammation in IL-2-deficient mice. J Immunol. 1997;158:566-573([PubMed: 8992969]).

5. Silk DB P-JJ. Inflammatory bowel disease: nutritional implications and treatment. . Proc Nutr Soc. 1989([PubMed: 2515542]):48:355-61.

6. Rigaud D AL, Cerf M, et al. Mechanisms of decreased food intake during weight loss in adult Crohn's disease patients without obvious malabsorption. Am J Clin Nutr. 1994([PubMed: 7942586]):60:775-81.

7. De Gaetano A GA, Benedetti G, et al. Increased resting lipid oxidation in Crohn's disease. J Parenter Enteral Nutr (JPEN). 1996( [PubMed: 8788261]):20:38-42.

8. Rutgeerts P VS, Van Assche G. Mucosal healing in inflammatory bowel disease: impossible ideal or therapeutic target? Gut 2007:56:453-5.

9. Jain S. GV, Naseem S. Acute-phase proteins: as diagnostic tool. J Pharm Bioallied Sci. 2011:3: 11827.
10. Blake G.J. RPM. Novel clinical markers of vascular wall inflammation. Circ Res. 2001:89: 763-71.

11. Murphy T.M. BLL, Beaman K.D. Extrahepatic transcription of human C-reactive protein. J Exp Med. 1991:173: 495-8.

12.Vermeire S. VAG, Rutgeerts P. C-reactive protein as a marker for inflammatory bowel disease. Inflamm. Bowel Dis J. 2004;10:661-5.

13. GC. K. The role of depot fat in the hypothalamic control of food intake in the rat. . Proc R Soc Lond B Biol Sci 1953:140: 578-96.

14. Zhang F BM, Beals JM, Briggs SL, Churgary LM, Clawson DK, et al. Crystal structure of the obese protein leptin -E100. . Nature 1997:387: 206-9.

15. Briley LP SL. Leptin and renal disease. Semin in Dial. 2006:19:54.

16. Cammisotto PG BM. Leptin secretion by white adipose tissue and gastric mucosa. Histol Histopathol. 2007:22:199-210.

17. Karmiris K KI, Kouroumalis EA. . Leptin, adiponectin, resistin, and ghrelin - implications for inflammatory bowel disease. Mol Nutr Food Res. 2008:52:855-66. [PubMed: 18383234].

18. Nishi Y. IH, Ueno H, Ohnita K. Plasma leptin and ghrelin concentrations in patients with Crohn's disease. World J Gastroenterol. 2005:11:7314-7.

19. Saladin R D-VP, Guerre-Millo M, et al. Transient increase in obese gene expression after food intake or insulin administration. Nature. 1995 377:527-9.

20. Adams, D. H. Sleisenger and Fordtran's Gastrointestinal and Liver Disease. Gut 56, 11751175 (2007).

21. Pithawa, A. Sleisenger and Fordtran's Gastrointestinal and Liver Disease: pathophysiology, diagnosis, management. Medical Journal Armed Forces India 63, 205 (2007).

22. Schäfflr A SJ, Büchler C. Mechanisms of disease: adipocytokines and visceral adipose tissueemerging role in intestinal and mesenteric diseases. Nat Clin Pract Gastroenterol Hepatol. 2005:2: 10311.

23. G. Biesiada JC, A. Ptak-belowska et al. Expression and release of leptin and proinflammatory cytokines in patients with ulcerative colitis and infectious diarrhea. journal of physiology and pharmacology 2012:63, 5, 471-81. 
24. Loftus CG LEJ, Harmsen WS, et al. Update on the incidenceand prevalence of Crohn's disease and ulcerative colitis in Olmsted County, Minnesota 1940-2000. Inflmm Bowel Dis. 2007:13:254-61.

25. Dong J CY, Tang Y, Xu F, Yu C, Li Y, et al. Body Mass Index Is Associated with Inflammatory Bowel Disease: A Systematic Review and Meta-Analysis. PLoS ONE 10. 2015;12.
26. Fagan E.A. DRF, Maton P.N., Hodgson H.J., Chadwick V.S.,, Petrie A. PMB. Serum levels of C-reactive protein in Crohn's disease and ulcerative colitis. Eur J Clin Invest. 1982:12: 351-9.

27. Hoppin AG KL, Zurakowski D, Leichtner AM, Bousvaros A. Serum leptin in children and young adults with inflammatory bowel disease. J Pediatr Gastroenterol Nutr 1998(26:500-505. ). 